\title{
Synthesis of Precision Poly(1,3-adamantylene alkylene)s via Acyclic Diene Metathesis Polycondensation
}

Jonas Friebel, ${ }^{\dagger,}$ Christopher P. Ender, ${ }^{\dagger}$ Markus Mezger, ${ }^{\dagger, \S ®}$ Jasper Michels, $^{\dagger}{ }^{\dagger}$ Manfred Wagner, ${ }^{\dagger}$

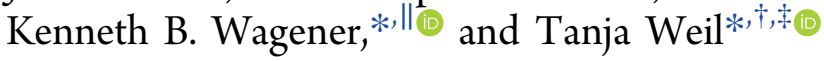

${ }^{\dagger}$ Max Planck Institute for Polymer Research, Ackermannweg 10, 55128 Mainz, Germany

${ }^{\ddagger}$ Institute of Inorganic Chemistry I, Ulm University, Albert-Einstein-Allee 11, 89081 Ulm, Germany

${ }^{\S}$ Institute of Physics, Johannes Gutenberg University Mainz, Ackermannweg 10, 55128 Mainz, Germany

"The George and Josephine Butler Polymer Research Laboratory Department of Chemistry, University of Florida, Gainesville, Florida 32611, United States

Supporting Information

ABSTRACT: Fully saturated, aliphatic polymers containing adamantane moieties evenly distributed along the polymer backbone are of great interest due to their exceptional thermal stability, yet more synthetic strategies toward these polymers would be desirable. Herein, we report for the first time the synthesis of poly(1,3-adamantylene alkylene)s based on $\alpha, \omega$ dienes containing bulky 1,3-adamantylene defects precisely located on every 11 th, 17 th, 19 th, and 21 st chain carbon via acyclic diene metathesis polycondensation. All saturated polymers revealed excellent thermal stabilities (452-456 ${ }^{\circ} \mathrm{C}$ ) that were significantly higher compared to those of

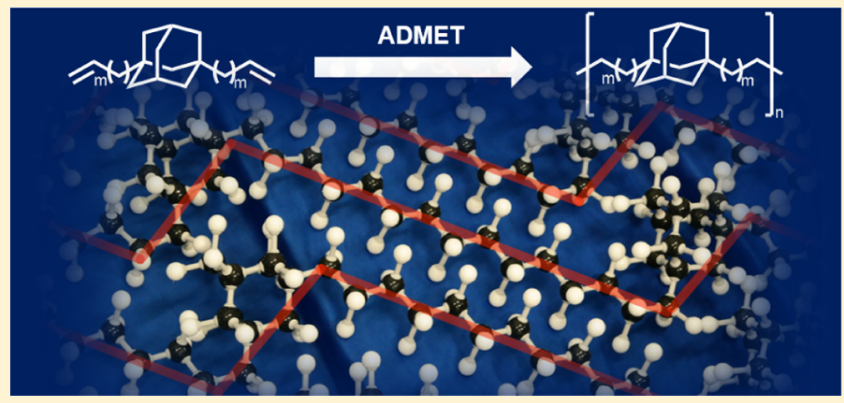
structurally similar polyolefins with aliphatic or aromatic ring systems in the backbone of polyethylene (PE). Their crystallinity increases successively from shorter to longer $\mathrm{CH}_{2}$ chains between the adamantane defects. The adamantanes were located in the PE crystals distorting the PE unit cell by the incorporation of the adamantane defect at the kinks of a terrace arrangement. Precise positioning of structural defects within the polymeric backbone provides various opportunities to customize material properties by "defect engineering" in soft polymeric materials.

\section{INTRODUCTION}

Adamantane (tricyclo[3.3.1.1 $\left.1^{3,7}\right]$ decane) consists of three fused cyclohexyl rings, making it superimposable to the lattice of diamond. ${ }^{1,2}$ Adamantane is commonly functionalized at the tertiary bridgehead positions affording mono- up to tetrafunctionalized derivatives. Many different adamantanes have been synthesized ${ }^{3,4}$ and due to the high thermal and chemical stability of their aliphatic, rigid, and bulky cage structures, they were used as monomers or co-monomers in polymer chemistry. ${ }^{5-10}$ Nevertheless, there are just a few examples of fully aliphatic hydrocarbon polymers containing adamantane groups. On the one hand, polymers containing adamantyl moieties in the side chain have been generated by utilizing $\alpha$-olefines, ${ }^{11,12}$ alkynes, ${ }^{13} 1,3$-butadienes, ${ }^{14,15}$ and $\alpha, \omega$ dienes. ${ }^{16}$ On the other hand, bifunctional 1,3-adamantylene moieties have been exploited for manufacturing polymers with adamantyl moieties directly in the backbone. The synthesis of such polymers, however, remains challenging.

First examples of these polymers with adamantane groups in the backbone were reported by employing consecutive Wurtz coupling reactions of $3,3^{\prime}$-dibromo-1,1'-diamantane to afford poly(1,3-adamantane) $\mathbf{1 .}^{17}$ Similar polymers were also synthesized by ring-opening polymerization of distorted 1,3- dehydroadamantanes. ${ }^{18}$ However, the resulting polymers were insoluble in common organic solvents, which greatly aggravated their characterization.

The introduction of butyl groups to 1,3-dehydroadamantane afforded polymers 2 and 3 . which exhibited, in comparison to 1, improved solubility in organic solvents, which facilitated the characterization of the polymeric structure. ${ }^{19,20} \operatorname{Poly}(1,3-$ adamantane)s $\mathbf{2}$ and $\mathbf{3}$ are amorphous materials, whereas the bulky, rigid adamantane group in the poly(1,3-adamantane) polymers reported herein leads to polymers with high glass transition and decomposition temperatures. By gradually increasing the methylene content between two adamantane groups within these polymers, a change in crystallinity from amorphous to semicrystalline is expected. However, studies on the crystallization behavior of fully aliphatic hydrocarbon polymers bearing an adamantane group are rare. Comprehensive studies on the thermal and structural properties of polyethylene (PE) with precisely placed branches along the polymer backbone have been reported previously. ${ }^{16,21}$ When

Received: February 11, 2019

Revised: $\quad$ May 14, 2019 
an adamantane group was placed in the side chain of PE on every 21 methylene chain carbon, a bimodal melting curve with poor crystallinity $\left(T_{\mathrm{m}}=-8{ }^{\circ} \mathrm{C}, \Delta H_{\mathrm{m}}=2 \mathrm{~J} / \mathrm{g} ; T_{\mathrm{m}}=17^{\circ} \mathrm{C}\right.$, $\Delta H_{\mathrm{m}}=8 \mathrm{~J} / \mathrm{g}$ ) was observed. ${ }^{16}$ The adamantane defect in the $\mathrm{PE}$ side chain has a considerable impact on the PE crystal lattice, and it has been suggested that it is located outside the crystal (for alkyl defects < butyl). ${ }^{22,23}$ Interestingly, cyclic defects like phenylene and cyclohexylene in the backbone of PE showed good crystallinity and high melting points. ${ }^{24,25}$ Furthermore, other sterically demanding cyclic defects as phenylene- and cyclohexylene ethers ${ }^{26-28}$ in the main chain of PE have been analyzed with wide- and small-angle X-ray scattering (WAXS and SAXS, respectively). These defects were proven to be included in the PE lattice. We investigated the thermal and structural behavior of regularly spaced 1,3adamantylene groups within a PE chain (P-1,3-Ad-Z, Z = 10-20) with up to 20 methylene chain carbons precisely positioned between two adamantane groups (Figure 1). The

previous work:

- Wurtz coupling reaction

- Ring-opening polymerization

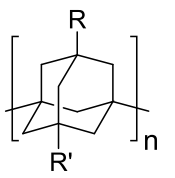

$R, R^{\prime}=H, 1$

$\mathrm{R}, \mathrm{R}^{\prime}=\mathrm{H}, \mathrm{nC}_{4} \mathrm{H}_{9}, 2$

$\mathrm{R}, \mathrm{R}^{\prime}=\mathrm{nC}_{4} \mathrm{H}_{9}, 3$

present work:

- ADMET polymerization

- tunable methylene spacers

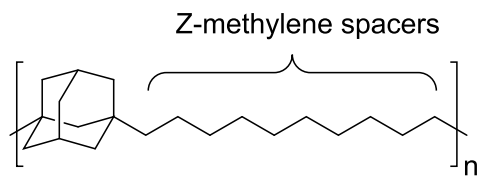

P-1,3-Ad-Z

$Z=10,16,18,20$

Figure 1. Overview of different synthetic strategies for $\operatorname{poly}(1,3-$ adamantylene)s.

resulting polymers showed high thermal stability and semicrystalline behavior with a tendency toward increasing crystallinity with increasing distances between adamantane defects. We envision that "defect engineering", i.e., the controlled positioning of structural defects in polymers, provides a unique opportunity to tune the properties in soft polymeric materials.

\section{RESULTS AND DISCUSSION}

Monomer Synthesis. A synthesis procedure for symmetrical alkyl branched acyclic diene metathesis (ADMET) monomers was described based on the two-step double alkenylation of primary nitriles with two equivalents of $\alpha, \omega$ alkenylbromides subsequently followed by reductive decyanation. ${ }^{29,30}$ A similar synthetic strategy was applied to secondary dinitriles as reported for cyclohexane-1,4-dicarbonitrile ${ }^{25}$ to create ADMET monomers with cyclic defects along the monomer chain. We used the copper-catalyzed $C\left(\mathrm{sp}^{3}\right)-\mathrm{C}\left(\mathrm{sp}^{3}\right)$ cross-coupling protocol from Kambe and co-workers to evenly distribute the adamantane defects along $\alpha, \omega$-dienes. In this protocol, primary alkyl halides were coupled with alkyl Grignard reagents in the presence of 1-phenylpropyne as a ligand, giving products in nearly quantitative yields. ${ }^{31}$ The ligand efficiently suppressed the $\beta$-hydride elimination of alkylmetal intermediates, which would also trigger isomerization, elimination, and/or reduction of the alkyl moieties. ${ }^{32}$ We applied this protocol in a 2 -fold copper-catalyzed alkylalkyl cross-coupling reaction with 1,3-bis(2-bromoethyl)adamantane (4) to generate 1,3-adamantylene units along the monomer chain. Commercially available dicarboxylic acid 5 was converted in three steps of esterification, reduction, and bromination to the desired dibromo building block 4 with an overall yield of $71 \%$. Monomers (M-1,3-Ad-m) were synthesized in the copper-catalyzed 2 -fold $\mathrm{C}\left(\mathrm{sp}^{3}\right)-\mathrm{C}\left(\mathrm{sp}^{3}\right)$ cross-coupling reaction of 1,3-bis(2-bromoethyl)adamantane (4) and freshly prepared $\omega$-chloromagnesium- $\alpha$-alkenes in the presence of the ligand 1-phenylpropin (6) in yields up to $74 \%$ (M-1,3-Ad-8) (Scheme 1).

ADMET Polymerization and Hydrogenation of Unsaturated Polymers. Monomers (M-1,3-Ad-m) were polymerized in bulk with Grubbs catalyst 1st generation at $65-70{ }^{\circ} \mathrm{C}$ in vacuo $\left(10^{-3} \mathrm{mbar}\right)$, yielding viscous unsaturated polymers followed by the exhaustive hydrogenation of all ADMET polymers using 4-methylbenzenesulfonhydrazide (TSH) and tripropylamine (TPA) at $135{ }^{\circ} \mathrm{C}$, ensuring no premature precipitation to produce the fully saturated ADMET polymers. ${ }^{33}$ The completion of the hydrogenation reaction was confirmed by the disappearance of the internal alkene at 5.4 ppm in ${ }^{1} \mathrm{H}$ NMR (Figure 2). The molecular weights were determined with gel permeation chromatography (GPC) and are collected in Figure 3 and Table 1.

Thermal Behavior of Saturated Polymers P-1,3-Ad(10-20) and CP-1,3-Ad-16/18/20. The thermal stability of the saturated polymers was measured from thermogravimetric analysis (TGA), and the corresponding thermograms are shown in Figure 4A. The onset temperature of thermal degradation was measured in inert nitrogen atmosphere and determined for $5 \%$ mass loss $\left(T_{\mathrm{d}, 5 \%}\right)$. The thermal degradation in all ADMET polymers occurred in a single step at all temperatures, and all polymers revealed excellent thermal stabilities with similar decomposition temperatures above 450 ${ }^{\circ} \mathrm{C}$, which decreased slightly in the order from P-1,3-Ad-10 to P-1,3-Ad-20. P-1,3-Ad-10 has the highest onset temperature of thermal degradation of $T_{\mathrm{d}, 5 \%}=456{ }^{\circ} \mathrm{C}$ (Figure $4 \mathrm{~A}$ ).

High-density polyethylene (HDPE) has a decomposition temperature onset of $441{ }^{\circ} \mathrm{C}$ (Figure 4A), which is about the same as the herein-synthesized adamantane ADMET polymers. Furthermore, similar polyolefins with ring systems in the backbone like poly( $p$-cyclohexylene alkylene)s PPC or poly $(p$ phenylene alkylene)s PPP are significantly thermally less stable than P-1,3-Ads (Figure 4B). ${ }^{24,25}$ The tricyclic, rigid cage structure of adamantane with low ring strain provides excellent thermal stability, and the adamantane moieties along the PE chain could stabilize the entire polymer chain to render P-1,3Ads thermally very stable.

Crystallization Behavior. The melting temperatures $\left(T_{\mathrm{m}}\right)$ of all ADMET polymers were measured by nonisothermal differential scanning calorimetry (DSC). The polymer with the shortest alkyl chain between the adamantane units, P-1,3-Ad- 
Scheme 1. (A) Synthesis of Symmetric $\alpha, \omega$-Dienes (M-1,3-Ad-m) Containing 1,3-Adamanantylene Moieties; (B)

Polymerization of Monomers (M-1,3-Ad-m) Followed by the Exhaustive Hydrogenation to Obtain Saturated Polymers P-1,3Ad-Z and Copolymers cP-1,3-Ad-16/18/20

A Monomer synthesis
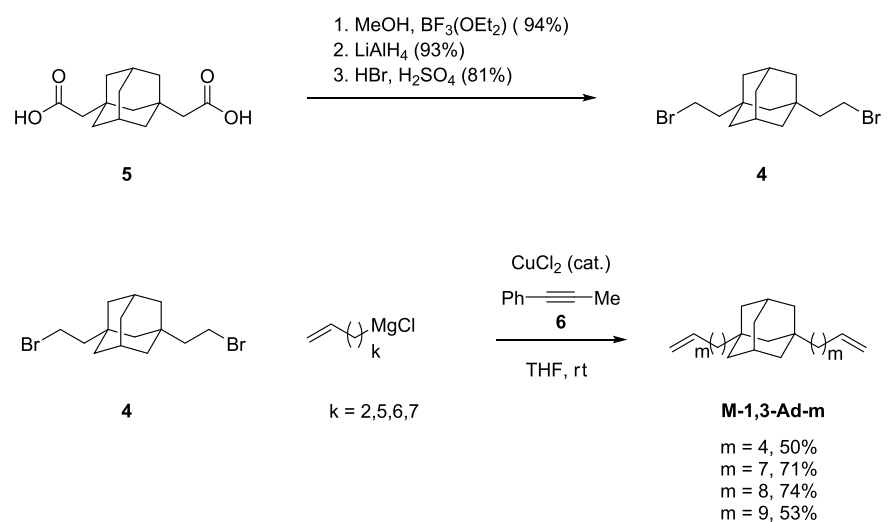

B Polymerization and hydrogenation
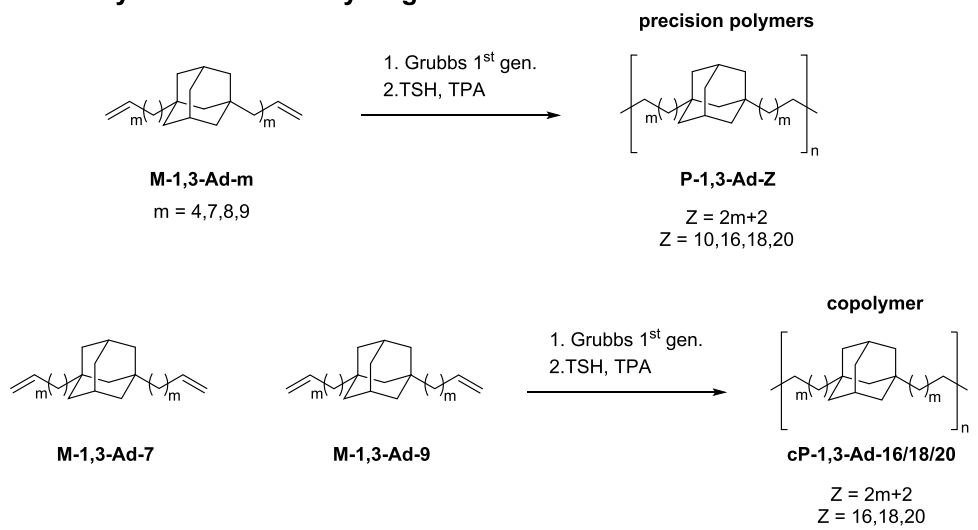

A
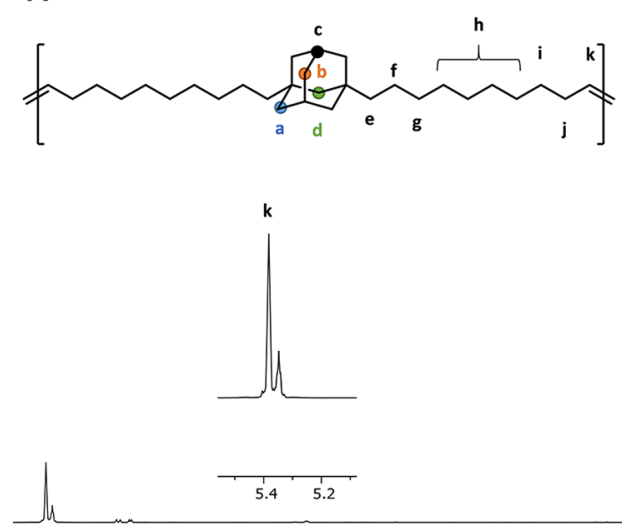

\section{B}
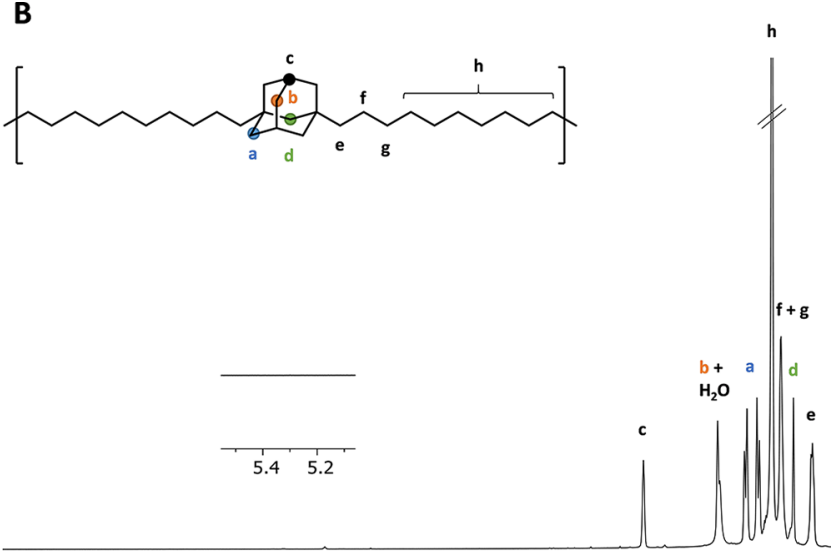

$\begin{array}{llllllllllllllllllllllllllll}5.4 & 5.2 & 5.0 & 4.8 & 4.6 & 4.4 & 4.2 & 4.0 & 3.8 & 3.6 & 3.4 & 3.2 & 3.0 & 2.8 & 2.6 & 2.4 & 2.2 & 2.0 & 1.8 & 1.6 & 1.4 & 1.2 & 1.0\end{array}$

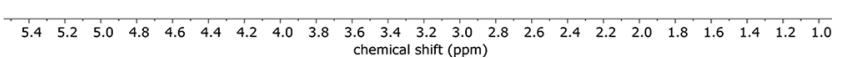

Figure 2. Representative ${ }^{1} \mathrm{H}$ NMR spectra in $\mathrm{CDCl}_{3}$ of (A) unsaturated polymer uP-1,3-Ad-20. (B) The internal double bond disappears upon exhaustive hydrogenation.

10 with 10 methylene groups, was completely amorphous. P1,3-Ad-16 showed a semicrystalline behavior with a melting point at $T_{\mathrm{m}}=58^{\circ} \mathrm{C}$. By increasing the methylene chain lengths to 18 and 20 methylene groups between the adamantane defects, the crystallinity of the PE polymers increases. We found increased melting points for P-1,3-Ad-18 $\left(T_{\mathrm{m}}=62{ }^{\circ} \mathrm{C}\right)$ and P-1,3-Ad-20 $\left(T_{\mathrm{m}}=63{ }^{\circ} \mathrm{C}\right)$ and the heat of fusion for the melting process was highest for P-1,3-Ad-20 $\left(\Delta H_{\mathrm{m}}=35 \mathrm{~J} / \mathrm{g}\right)$. This trend is likely due to the steady decline in the defect-tochain ratio. Nevertheless, the regularity of methylene units between two defects also plays an important role. We synthesized the copolymer cP-1,3-Ad-16/18/20 in copolymerization of an equimolar mixture of M-1,3-Ad-7 and M-1,3Ad-9, followed by hydrogenation to obtain randomly 


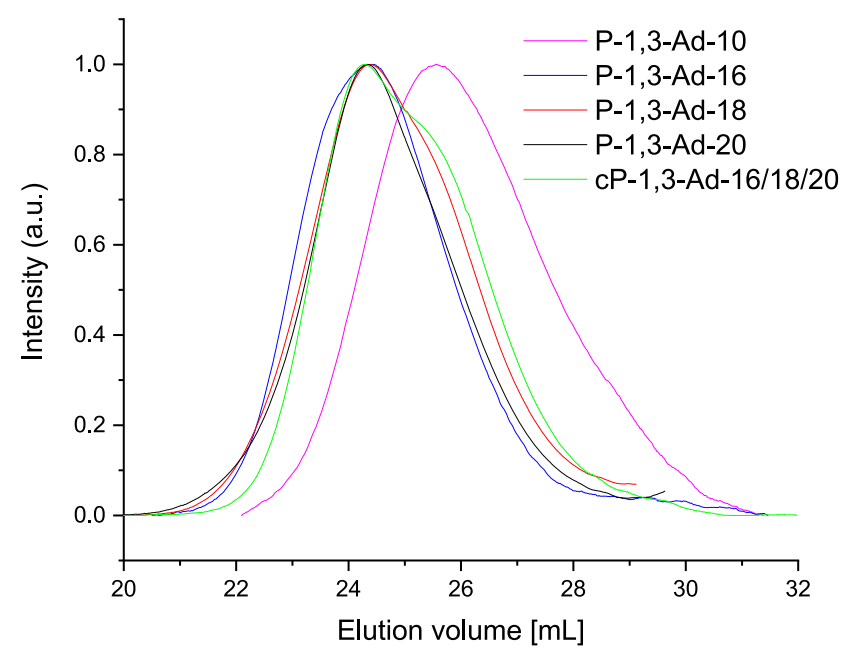

Figure 3. GPC traces of P-1,3-Ad-Z and cP-1,3-Ad16/18/20 was determined by chloroform GPC by using PS calibration standards.

Table 1. Characterization of Saturated ADMET Polymers

\begin{tabular}{lcccccr} 
& $\begin{array}{c}M_{\mathrm{w}}{ }^{a} \\
(\mathrm{kDa})\end{array}$ & $\Xi^{a}$ & $\begin{array}{c}T_{\mathrm{m}}{ }^{b} \\
\left({ }^{\circ} \mathrm{C}\right)\end{array}$ & $\begin{array}{c}\Delta H_{\mathrm{m}}{ }^{b} \\
(\mathrm{~J} / \mathrm{g})\end{array}$ & $\begin{array}{c}T_{\mathrm{d}, 5 \%}{ }^{c} \\
\left({ }^{\circ} \mathrm{C}\right)\end{array}$ & $\begin{array}{r}X_{\mathrm{c}}{ }^{b} \\
(\%)\end{array}$ \\
\hline P-1,3-Ad-10 & 16.5 & 1.72 & & & 456 & \\
P-1,3-Ad-16 & 32.2 & 1.50 & 59 & 12 & 453 & 4.1 \\
P-1,3-Ad-18 & 35.2 & 1.91 & 62 & 34 & 454 & 11.6 \\
P-1,3-Ad-20 & 32.7 & 1.98 & 63 & 35 & 452 & 11.9 \\
cP-1,3-Ad-16/18/20 & 25.7 & 1.84 & 42 & 24 & 452 & 8.2
\end{tabular}

${ }^{a}$ Determined by gel permeation chromatography (GPC). ${ }^{b}$ Determined by differential scanning calorimetry (DSC), the crystallinity $\left(X_{\mathrm{c}}\right)$ was calculated from $\Delta H_{\mathrm{m}}$ in relation to $100 \%$ crystalline PE $\left(\Delta H_{\mathrm{m}, \mathrm{PE}}=293 \mathrm{~J} / \mathrm{g}\right) .{ }^{c}$ Determined by thermogravimetric analysis (TGA). distributed polymers of 16,18 , and 20 methylene units between two defects (Scheme 1). The average length of methylene spacers is 18 units in these copolymers. Compared to the precision polymer P-1,3-Ad-18 with exactly 18 methylene spacer units, the copolymer cP-1,3-Ad-16/18/20 has a lower melting point $\left(T_{\mathrm{m}}=42^{\circ} \mathrm{C}\right)$, as well as a lower heat of fusion $\left(\Delta H_{\mathrm{m}}=24 \mathrm{~J} / \mathrm{g}\right)$ (Table 1). Both parameters indicate that the copolymer is less crystalline than their precision polymer equivalents $\mathbf{P}-\mathbf{1}, \mathbf{3}-\mathbf{A d}-\mathbf{1 8}$ and P-1,3-Ad-20 because the random methylene distribution most likely disturbs the polymer packing (Figure 7). Interestingly, all semicrystalline polymers showed melting-recrystallization behavior at moderate heating rates of $10 \mathrm{~K} / \mathrm{min}$ (Figure $5 \mathrm{~A}$ ). Most likely, the polymers did not fully crystallize during the cooling process, so metastable crystals were formed. Upon heating, these imperfect crystals melt and immediately recrystallized to form more stable crystals with higher melting temperatures, $T_{\mathrm{m}}$. Indeed in the cooling process, a high degree of supercooling is required to crystallize those polymers (Figure 5B) that have the largest difference in melting and crystallizing temperatures such as $\mathbf{P}$ 1,3-Ad-16 $\left(\Delta T=62{ }^{\circ} \mathrm{C}\right)$, which underlines the challenges to crystallize this polymer. We also investigated the thermal behavior of P-1,3-Ad-20 using different cooling and heating rates $(0.5,5,10$, and $50 \mathrm{~K} / \mathrm{min}$, Figure $5 \mathrm{C}, \mathrm{D})$. At the highest heating rate $(50 \mathrm{~K} / \mathrm{min})$, the most distinctive meltingcrystallization-melting behavior was observed.

This behavior was gradually diminished by applying slower heating rates. Eventually, a single melting mode for $0.5 \mathrm{~K} / \mathrm{min}$ was observed, where the polymer was given sufficient time for melting and crystallization (Figure 5C). Allowing the polymer more time to crystallize gradually suppresses the degree of supercooling for slower cooling rates (Figure 5D). To further demonstrate the significant influence that the bulky adamantyl groups impose on the crystallization behavior of the polymers,
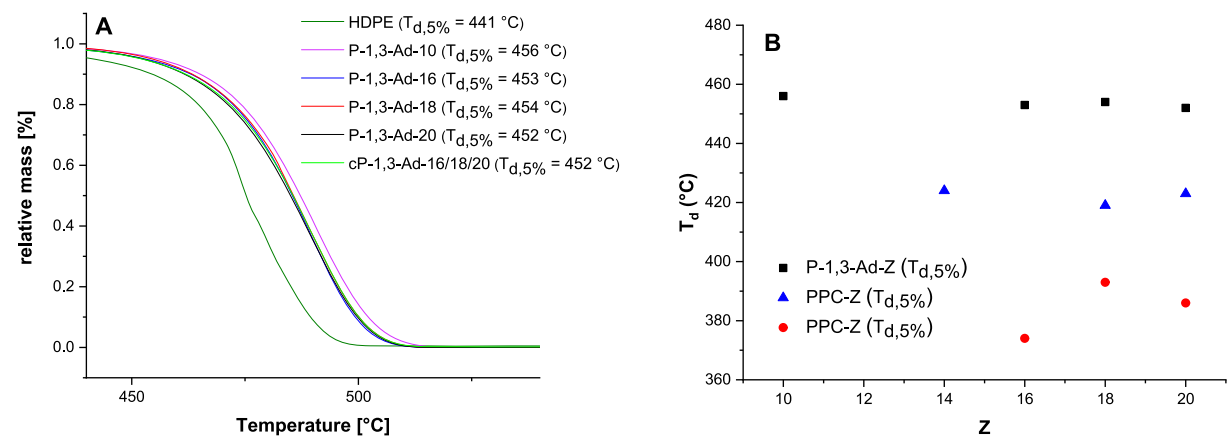

C

present work:

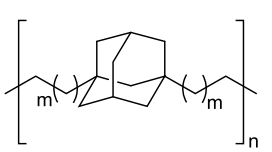

cis P-1,3-Ad ref 25<smiles>CCCC1CCC(N=CC(C)C)CC1</smiles>

PPC ref 24

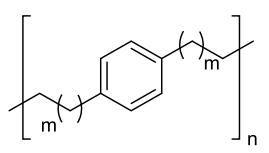

PPP

cis/ trans Isomers

Figure 4. A) Thermogravimetric analysis (TGA) of P-1,3-Ad-(10-20), cP-1,3-Ad-16/18/20, and HDPE. (B) Comparison of the onset temperatures of thermal degradation $T_{\mathrm{d}, 5 \%}$ (temperature where $5 \%$ mass loss occurs) of adamantylene (P-1,3-Ad), cyclohexylene (PPC), and phenylene (PPP) in the backbone of PE, where $Z$ indicates the number of methylene units between the defects. Structural overview of these polymers is shown in (C). Adamantylene defects of P-1,3-Ad are in all cis configuration, unlike those of PPCs, which have been synthesized as cis/ trans isomers. ${ }^{25}$ 

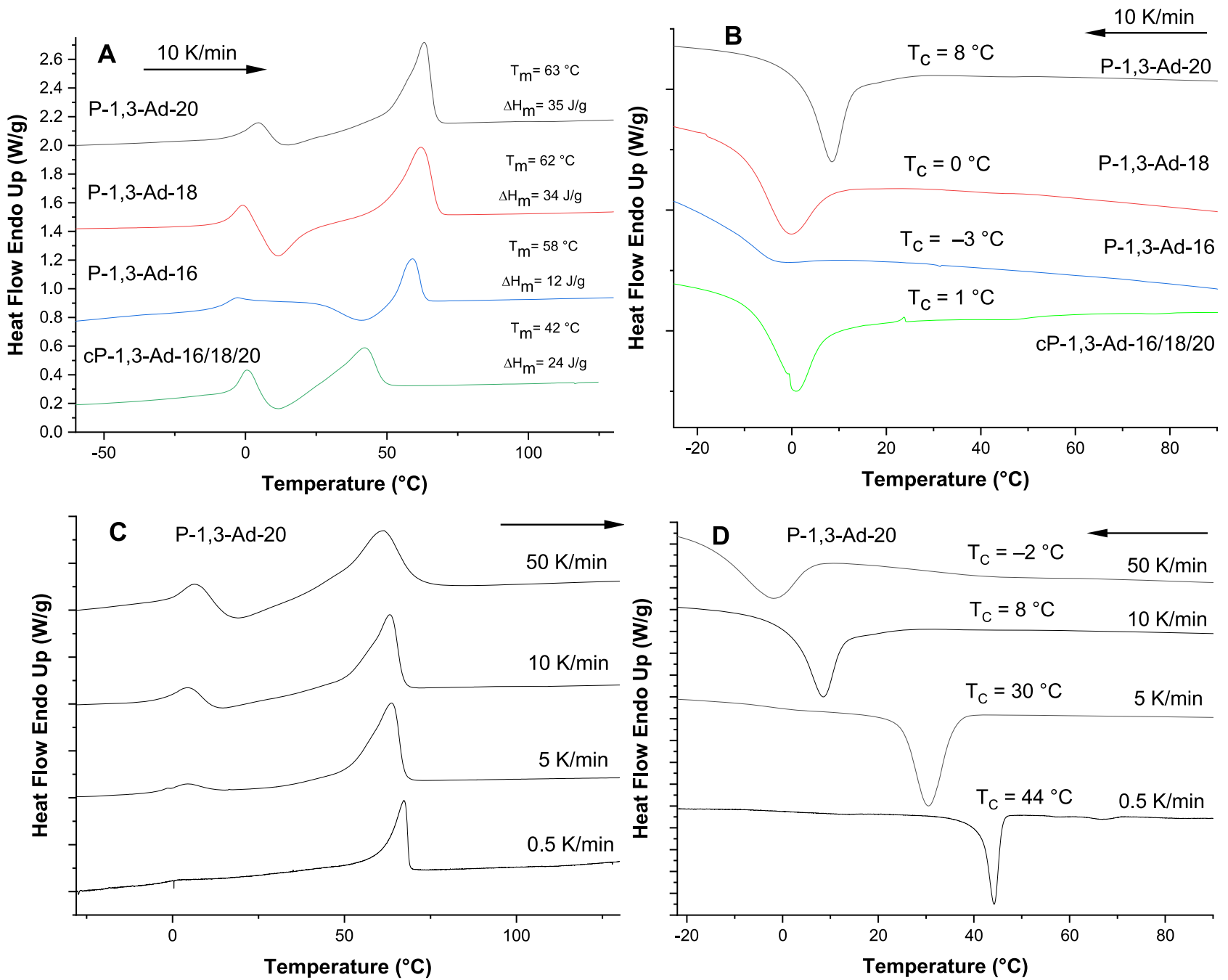

Figure 5. Differential scanning calorimetry (DSC). (A) Precision polymers P-1,3-Ad (16-20) and copolymer cP-1,3-Ad-16/18/20 at heating rates of $10 \mathrm{~K} / \mathrm{min}$ and (B) for cooling rates of $10 \mathrm{~K} / \mathrm{min}$. (C) P-1,3-Ad-20 at different heating rates $(50,10,5$, and $0.5 \mathrm{~K} / \mathrm{min})$ and (D) cooling rates $(50,10,5$, and $0.5 \mathrm{~K} / \mathrm{min})$.
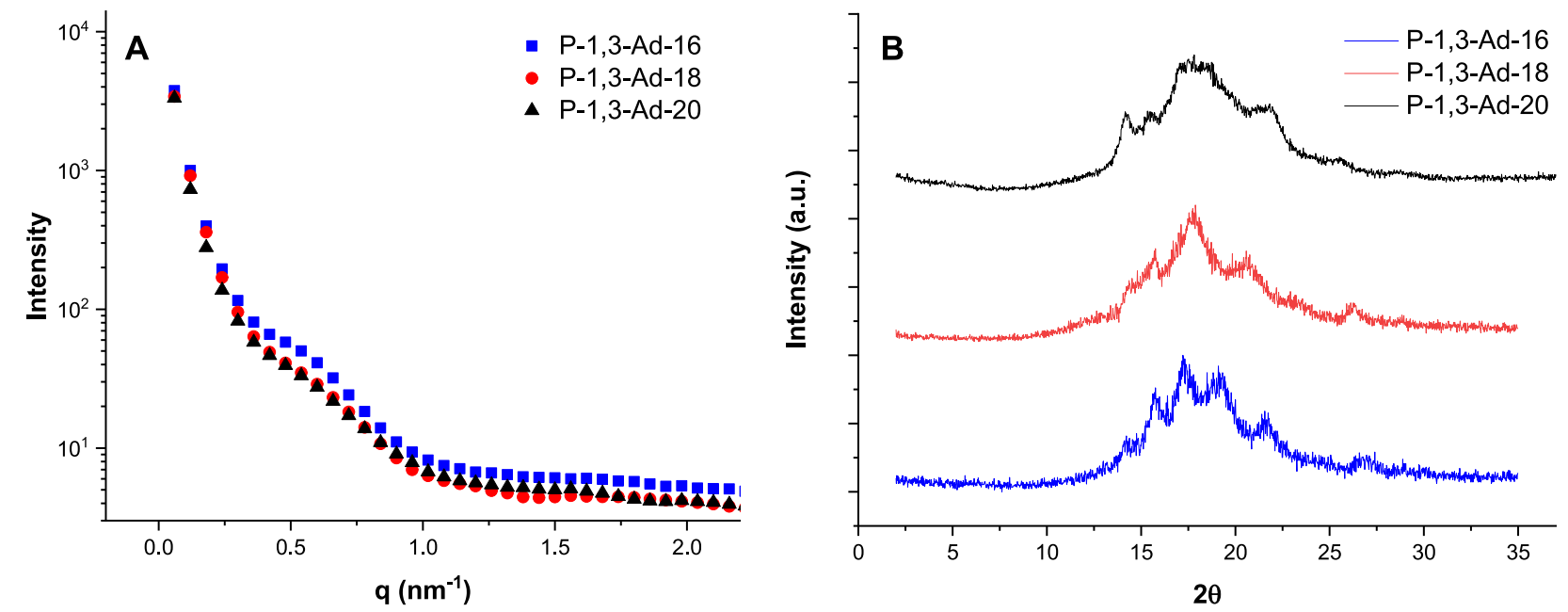

Figure 6. (A) SAXS profile of P-1,3-Ad (16-20) after being cooled from $68{ }^{\circ} \mathrm{C}$ to room temperature and (B) WAXS pattern of P-1,3-Ad (1620).

we performed a Hoffman-Weeks analysis on P-1,3-Ad-20 (Figure S11). The figure shows that the small melting peak corresponding to the metastable state increases with crystallization temperature, in agreement with the cooling runs in Figure 5D, and is likely explained by the crystal becoming "more perfect" at lower undercooling. Interestingly, 
the position of the high-temperature peak corresponding to the thermodynamically more stable state remains unchanged. We showed similar behavior for the precision ADMET polymers with bulky phosphoesters in the main chain of PE. ${ }^{23}$ The explanation for the absence of a shift in the melting temperature is a suppression of lamellar thickening due to constrained sliding motion of the chain segments due to the presence of sterically bulky groups or defects. Furthermore, polarized optical microscopy (POM) measurements on P-1,3Ad-20 were performed before $\left(-30^{\circ} \mathrm{C}\right)$ and after $\left(25^{\circ} \mathrm{C}\right)$ the melting-recrystallization event, with no change in the crystallinity observed at the macroscopic level, indicating that the melting-recrystallization process takes place inside the crystals (Figure S10) in accordance with previous reports. ${ }^{28}$

PE with adamantane side chains (20 methylene carbon atoms per 1-adamantyl group) revealed crystallinity and a bimodal melting behavior. Compared to the adamantane defects placed in the backbone of PE as described herein, adamantane moieties in the side chain of PE impose larger steric hindrance; therefore, we observed significantly lower melting temperatures and heat of fusion values $\left(T_{\mathrm{m}}=-8{ }^{\circ} \mathrm{C}\right.$, $\left.\Delta H_{\mathrm{m}}=2 \mathrm{~J} / \mathrm{g} ; T_{\mathrm{m}}=17{ }^{\circ} \mathrm{C}, \Delta H_{\mathrm{m}}=8 \mathrm{~J} / \mathrm{g}\right) .{ }^{16}$ Furthermore, the adamantane defects in the backbone are exclusively introduced in the cis-1,3 configuration, allowing the PE backbone to preserve its "natural" conformation without introducing structural distorsions. Until now, similar cyclic aliphatic defects, such as cyclohexylenes, have been polymerized, but their synthesis only afforded cis/trans isomer mixtures in ADMET polymerizations. The rigid adamantane scaffold locks the cyclohexyl rings in the armchair conformation and, therefore, substitution on the bridgehead position occurs without isomerization, making these 1,3 substituted adamantanes precisely defined building blocks within PE polymers (Figure 4C).

WAXS and SAXS. Melt-grown crystals were used for WAXS and SAXS measurements. Figure 6A shows the X-ray scattering patterns of all P-1,3-Ads polymers. The diffuse maximum observed at $q=0.5 \mathrm{~nm}^{-1}$ corresponds to a long period of $L=13 \mathrm{~nm}$. This periodicity was significantly larger than those observed for alkyl-branched $\mathrm{PEs},{ }^{22,23}$ with the same $20 \mathrm{CH}_{2}$ spacers or the length of $2.54 \mathrm{~nm}$ for an all-trans $\mathrm{C}_{20}$ alkyl chain. Therefore, we conclude that the adamantane defects were incorporated in the crystalline parts of the lamellar structure. These bulky adamantane defects severely affected the PE lattice, which explains the complex diffraction pattern observed in WAXS. Unlike the characteristic (110) and (200) reflections of orthorhombic PE at 21.4 and $24.0^{\circ},{ }^{16}$ at least five partially overlapping reflections was identified between 14 and $27^{\circ}$ (Figure $7 \mathrm{~B}$ ).

These results were consistent with the formation of a triclinic lattice similar to the observations for metasubstituted phenylene ether defects in PE. ${ }^{28}$ Furthermore, the relatively weak Bragg reflections were consistent with the crystallinity of only $4.1-11.9 \%$ determined by DSC (Table 1 ).

To further understand the observed structure, we focused on the steric constraints within the interface between the amorphous and crystalline regions of the lamellar structure of a semicrystalline polymer. ${ }^{34}$ Flexible defects such as alkyl branches $^{22}$ can largely reside within the amorphous parts. Therefore, they occupy less space within the interfacial region. In contrast, the rigid near-spherical adamantane defects occupy a large cross section of $\sim 35 \AA^{2}$,, whereas the cross section of the crystalline alkyl chains is only $\sim 20 \AA^{2}$. Thus, the

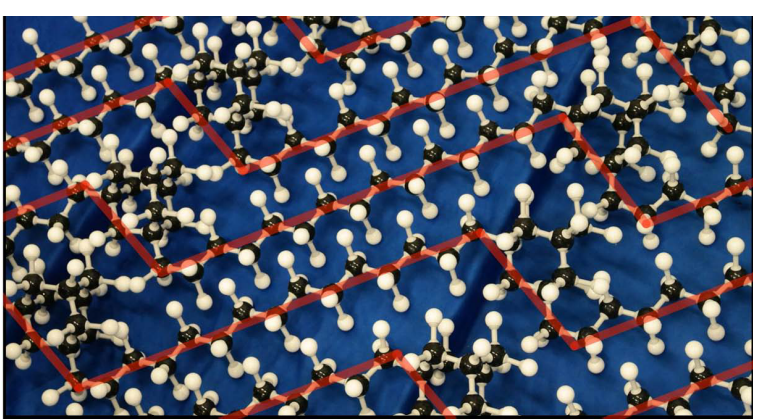

B

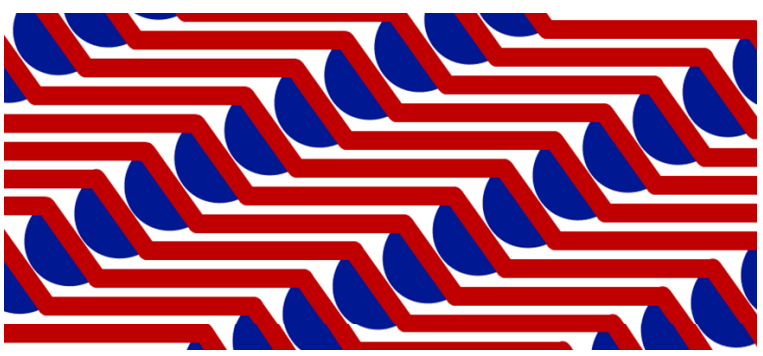

Figure 7. (A) Model for P-1,3-Ads. (B) Sketch of the proposed zigzag conformation of the polymer backbone (red lines), where the bulky adamantane defects are located at the kinks (blue half-spheres).

segregation of the bulky adamantane defects at this interface would require extensive polymer chain backfolding at adjacent reentry positions or a very large angle between the interface normal and the crystalline chains. In ortho-substituted phenylene ether defects, ${ }^{28}$ that are expelled from crystalline regions, the $\mathrm{PE}$ backbone turns by $180^{\circ}$. However, for the polymers investigated in this work, the main chain extended through the 1,3-substituted adamantane defects in all transconformation. Therefore, backfolding of the polymer chain at adjacent reentry sites is sterically impossible. Thus, the defects were included in the crystalline regions.

However, a crystal structure where bulky defects are arranged on an all-trans backbone as illustrated by Fan and co-workers ${ }^{28}$ does not exhibit reasonable molecular packing. Therefore, we suggest that the backbone buckles through the adamantane defects (Figure 7). This zig-zag conformation allows stacking in terraces and a space-filling three-dimensional crystal. Here, the majority of adjacent aliphatic chains can orient in parallel in close vicinity to each other, whereas the adamantane defects are located at the kinks. Nevertheless, the sterically demanding adamantane defects impose constraints on the stacking offset and kink angle. This could considerably distort the PE unit cell, leading to the multiple observed Bragg peaks in contrast to the orthorhombic PE crystal structure. The model is also supported by the observation we made for the copolymer cP-1,3-Ad-16/18/20, which consists of randomly distributed methylene chain lengths of 16,18 , and 20 units, causing a lower melting point and $\Delta H_{\mathrm{m}}$ value compared to the precision polymers $\mathbf{P}-\mathbf{1}, \mathbf{3}-\mathbf{A d}-\mathbf{1 8}$ and P-1,3-Ad-20, indicating a lower crystallinity.

Based on the measured heat of fusion and long period of $\Delta H_{\mathrm{m}}=35 \mathrm{~J} / \mathrm{g}$ and $L=13 \mathrm{~nm}$, as well as an approximate model that assumes volume-weighted contributions from the adamantly and $n$-alkyl regions in the crystal structure (see Supporting Information), we observed a lower limit for the lamellar thickness in P-1,3-Ad-20 of $2.6<l<3.2 \mathrm{~nm}$, roughly corresponding to effectively $1.1-1.4$ kinked monomer units 
traversing the crystalline lamella if the chains are oriented orthogonal to the lamellar surface. This number increases to $\sim 1.9$ to 2.7 monomers if the adamantane units are assumed to orient parallel to the same. Assuming an equilibrium melting temperature for the crystal similar to that of neat $\mathrm{PE}$, i.e., $T_{\mathrm{m}}^{0}=$ $414 \mathrm{~K}$, the model (eq S2) estimates a surface energy of $\sigma=$ $0.04 \mathrm{~J} / \mathrm{m}^{2}$, i.e., significantly lower compared to the fold surface of pristine PE lamellae $\left(\sigma=0.09 \mathrm{~J} / \mathrm{m}^{2}\right)$, when crystallized at comparable temperature, ${ }^{35}$ which supports our hypothesis that (tight) folds are absent in the present system due to steric constraints induced by the adamantane units.

\section{CONCLUSIONS}

A new synthesis procedure of poly(1,3-adamantylene)s with $10,16,18$, and $20 \mathrm{CH}_{2}$ atoms between two adamantane defects via $\mathrm{ADMET}$ polymerization reactions was developed. Monomers were obtained in 2-fold copper-catalyzed alkylalkyl cross-coupling reactions in good yields. All saturated polymers revealed excellent thermal stabilities $\left(452-456{ }^{\circ} \mathrm{C}\right)$. The thermal stabilities of these P-1,3-Ads were significantly higher than those of the structurally similar polyolefins with aliphatic or aromatic ring systems like cyclohexylene or phenylene in the backbone of PE. Furthermore, P-1,3-Ad16-20 showed semicrystalline behavior. The crystallinity increased successively from shorter to longer $\mathrm{CH} 2$ chains between the adamantane defects. From the SAXS measurements on P-1,3-Ad-16, P-1,3-Ad-18, and P-1,3-Ad-20, we obtained a lamellar periodicity of $13 \mathrm{~nm}$. This value was significantly larger than those observed for alkyl-branched PEs, where the defect was not located in the PE crystal. Supported by steric arguments, we conclude that the bulky adamantane defects are located inside the PE crystals. The results indicate that next to bulky and rigid adamantane moieties, backfolding of the polymer backbone to adjacent reentry sites is hindered. This interpretation is in line with observations in recent studies on cyclic ethers ${ }^{26-28}$ in the backbone of PE. Furthermore, the observation of multiple Bragg peaks in the WAXS regime could be explained by a distortion of the PE unit cell caused by the incorporation of the defect at the kinks of a terrace arrangement.

Our studies will contribute to an improved understanding of the impact of bulky adamantane defects along a polymer chain on the packing providing PE polymers with excellent stability to thermal treatment. We believe that the precise positioning of structural defects within the polymer backbone will provide many opportunities to customize material properties, paving the way to defect engineering in soft polymeric materials.

\section{EXPERIMENTAL SECTION}

Materials. 2,2'-(Adamantane-1,3-diyl)diacetic acid (Sigma, 97\%), boron trifluoride diethyl etherate (Acros, $48 \%$ in $\mathrm{Et}_{2} \mathrm{O}$ ), 4-chloro-1butene (Acros, 98\%), 9-chloro-1-nonene (flourochem, >95\%), 8chloro-1-octene (flourochem, >95\%), $\mathrm{CDCl}_{3}$ (Sigma, 99.8\%), copper(II) chloride $\left(\mathrm{CuCl}_{2}\right.$, Acros, anhydrous $\left.99 \%\right)$, Grubbs Catalyst 1st Generation (Sigma, 97\%), HDPE (Alfa Aesar, $M_{\mathrm{w}}=125 \mathrm{kDa}$ ), hydrobromic acid (Sigma, 47\% in $\mathrm{H}_{2} \mathrm{O}$ ), lithium aluminium hydride (Acros, 2.4 M in THF), magnesium purum, for Grignard reactions (Sigma, >99.5\%), 1-phenyl-1-propyne (Acros, 99\%), sulfuric acid (Fischer scientific, $>95 \%$ ), THF anhydrous (Sigma, $>99.9 \%$ inhibitor free), $p$-toluenesulfonyl hydrazide (Sigma, 97\%), tripropylamine (TCI, >98\%), $o$-xylol anhydrous (Sigma, 97\%) were used and flash column chromatography was performed on silica gel 60 (MachereyNagel GmbH, 40-63 $\mu \mathrm{m}, 230-400$ mesh).
Instrumentation and Characterization Techniques. Nuclear magnetic resonance (NMR) ${ }^{1} \mathrm{H}$ or ${ }^{13} \mathrm{C}$ measurements were recorded either on a BRUKER AVANCE III 850 or on a BRUKER AVANCE 700 NMR spectrometer at $298 \mathrm{~K}$ using the solvent signal as reference. The data were analyzed with MestReNova. The thermal properties of the synthesized polymers have been measured by differential scanning calorimetry (DSC) on a Mettler Toledo DSC $3^{+}$calorimeter. The analysis were performed in a $\mathrm{N}_{2}$ atmosphere $(30 \mathrm{~mL} / \mathrm{min})$ with a heating and cooling rates of 50, 10, 5, and $0.5 \mathrm{~K} / \mathrm{min}$. For nonisothermal crystallization, the samples were heated well above their melting points $\left(T=200{ }^{\circ} \mathrm{C}\right)$ to eliminate the thermal history. The DSC curves were recorded by cooling the sample from 200 to $-140{ }^{\circ} \mathrm{C}$ and by heating the sample from -140 to $200{ }^{\circ} \mathrm{C}$. For isothermal crystallization, the samples were heated well above their melting points $\left(T=200{ }^{\circ} \mathrm{C}\right)$ to eliminate the thermal history. The samples were then cooled to $0,10,20$, and $40{ }^{\circ} \mathrm{C}$, respectively, and kept at the designated temperature for $3 \mathrm{~h}$. The samples were than quenched $-50{ }^{\circ} \mathrm{C}$, and DSC measurements were performed at a heating of $5 \mathrm{~K} / \mathrm{min}$. TGA was carried out on a Mettler Toledo ThermoSTAR TGA/DSC $3^{+}$-Thermowaage in a nitrogen atmosphere. The samples were heated from room temperature (rt) to 700 ${ }^{\circ} \mathrm{C}$, with the $\mathrm{N}_{2}$ purging rate set as $30 \mathrm{~mL} / \mathrm{min}$. GPC experiments were performed using an Agilent Technologies 1260 instrument consisting of a pump, autosampler, and column oven. A column set consisting of 3 columns, SDV $10^{6} \AA$, SDV $10^{4} \AA$, and SDV $500 \AA$ (PSS Standards Service GmbH, Mainz, Germany), all of $300 \times 8 \mathrm{~mm}^{2}$ and $10 \mu \mathrm{m}$ average particle size, were used. Chloroform as the eluent was used at a flow rate of $1.0 \mathrm{~mL} / \mathrm{min}$ and a column temperature of $30{ }^{\circ} \mathrm{C}$. The injection volume was $200 \mu \mathrm{L}(3-5 \mathrm{mg} / \mathrm{mL})$. Detection was accomplished with a RI detector (Agilent Technologies Calibration) was carried out by using polystyrene standards provided by PSS Polymer Standards Service GmbH (Mainz, Germany). Data acquisition and evaluation was performed using PSS WINGPC UniChrom and Origin 8.0. Gas chromatography-mass spectrometry (GC-MS) was performed on a Shimadzu GC-2010 plus gas chromate-graph and QP2010 ultra-mass spectrometer with a fused silica column (7HG-G010-11, ZB-5MS) using the following program: helium carrier gas, injection temperature $310{ }^{\circ} \mathrm{C}$, detector temperature $310^{\circ} \mathrm{C}$, flow rate $0.88 \mathrm{~mL} / \mathrm{min}$, start temperature $50{ }^{\circ} \mathrm{C}$, heating rate $50{ }^{\circ} \mathrm{C} / \mathrm{min}$, and end temperature $310^{\circ} \mathrm{C}$ for $10 \mathrm{~min}$. The data were analyzed with OpenChrom. For wide-angle (WAXS) and smallangle X-ray scattering (SAXS) measurements, polymer foils of approximately $200 \mu \mathrm{m}$ thickness were prepared by pressing the raw molten materials between two PTFE foils. Subsequently, the foils were heated above their melting points $\left(1 \mathrm{~h}\right.$ at $\left.68^{\circ} \mathrm{C}\right)$ and slowly cooled to $38{ }^{\circ} \mathrm{C}$ (temperature rate $0.01 \mathrm{~K} / \mathrm{min}$ ) inside a closed cycle thermostat. WAXS measurements on crystalline samples were conducted on a powder diffractometer in Bragg Brentano geometry (Phillips PW1820, Cu anode). The SAXS data were obtained by an in-house instrument. ${ }^{36}$ For POM micrographs, the polymer was melted on a glass substrate, creating a film of approximately $100 \mu \mathrm{m}$. POM micrographs were taken at -30 and $25{ }^{\circ} \mathrm{C}$ with a Leica DM2700 $\mathrm{P}$ microscope after heating the film above the melting point $\left(15 \mathrm{~min}\right.$ at $\left.120{ }^{\circ} \mathrm{C}\right)$. Followed by cooling to $-30{ }^{\circ} \mathrm{C}$ (temperature rate $5 \mathrm{~K} / \mathrm{min}$ ) and heating to $25^{\circ} \mathrm{C}$ (temperature rate $5 \mathrm{~K} / \mathrm{min}$ ).

Synthetic Procedures. Synthesis of 1,3-bis(2-bromoethyl)adamantane (4): the dibromide (4) was synthesized with slightly changes to the protocol. ${ }^{37}$

General Experimental Procedure for Monomer Synthesis (M-1,3-Ad-m, $m=4,7,8,9)$. 1,3-Bis(2-bromoethyl)adamantane (4, 1.00 equiv) was placed in a flame-dried Schlenk tube. Freshly prepared Grignard solutions ( $1 \mathrm{~mol} / \mathrm{L}$ in THF) were synthesized according to the protocol ${ }^{38}$ and subjected to the Schlenk tube $(k=2$ (3.00 equiv), 5, 6, and 7 (6.00 equiv) ) followed by the addition of 1 phenyl-1-propyne (6, 2.00 equiv) and $\mathrm{CuCl}_{2}$ (0.02 equiv) at ambient temperature. The reaction mixtures were quenched with a solution of saturated aqueous $\mathrm{NH}_{4} \mathrm{Cl}$ and extracted with $n$-hexane. The crude products were purified by flash column chromatography. For the monomers (M-1,3-Ad-m, $\mathrm{m}=7,8,9)$, an additional distillation was required. 
1,3-Di(hex-5-en-1-yl)adamantane (M-1,3-Ad-4). Yield: 50\%. ${ }^{1} \mathrm{H}$ $\operatorname{NMR}\left(850 \mathrm{MHz}, \mathrm{CDCl}_{3}\right): \delta(\mathrm{ppm})=1.02-1.07(\mathrm{~m}, 4 \mathrm{H}), 1.12-1.15$ (m, $2 \mathrm{H}), 1.21-1.27(\mathrm{~m}, 4 \mathrm{H}), 1.30-1.43(\mathrm{~m}, 12 \mathrm{H}), 1.55-1.57(\mathrm{~m}$, $2 \mathrm{H}), 1.96-1.99(\mathrm{~m}, 2 \mathrm{H}), 2.03-2.07(\mathrm{~m}, 4 \mathrm{H}), 4.91-4.94(\mathrm{~m}, 2 \mathrm{H})$, $4.97-5.01(\mathrm{~m}, 2 \mathrm{H}), 5.81(\mathrm{ddt}, J=17.24,10.23,6.68 \mathrm{~Hz}, 2 \mathrm{H})$.

${ }^{13} \mathrm{C}$ NMR $\left(214 \mathrm{MHz}, \mathrm{CDCl}_{3}\right): \delta(\mathrm{ppm})=22.2,29.4,30.1,33.1$, 34.0, 37.0, 42.3, 44.5, 47.7, 114.2, 139.4. GC-MS (EI) $\mathrm{m} / z$ (relative intensity) $=300\left(\left[\mathrm{M}^{+}\right], 6\right), 217(100), 135(42), 121(30), 93$ (32), 91 (30), 81 (24), 55 (21), 41 (24).

1,3-Di(non-8-en-1-yl)adamantane (M-1,3-Ad-7). Yield: $71 \% .{ }^{1} \mathrm{H}$ $\operatorname{NMR}\left(850 \mathrm{MHz}, \mathrm{CDCl}_{3}\right): \delta(\mathrm{ppm})=1.01-1.07(\mathrm{~m}, 4 \mathrm{H}), 1.13-1.16$ $(\mathrm{m}, 2 \mathrm{H}), 1.19-1.26(\mathrm{~m}, 8 \mathrm{H}), 1.26-1.32(\mathrm{~m}, 8 \mathrm{H}), 1.32-1.44(\mathrm{~m}$, $12 \mathrm{H}), 1.56-1.59(\mathrm{~m}, 2 \mathrm{H}), 1.96-2.00(\mathrm{~m}, 2 \mathrm{H}), 2.03-2.07(\mathrm{~m}, 4 \mathrm{H})$, $4.91-4.95(\mathrm{~m}, 2 \mathrm{H}), 4.97-5.02(\mathrm{~m}, 2 \mathrm{H}), 5.82(\mathrm{ddt}, J=17.20,10.25$, $6.67 \mathrm{~Hz}, 2 \mathrm{H}) .{ }^{13} \mathrm{C}$ NMR $\left(214 \mathrm{MHz}, \mathrm{CDCl}_{3}\right): \delta(\mathrm{ppm})=22.7,29.2$, 29.3, 29.5, 29.7, 30.8, 33.2, 34.0, 37.2, 42.5, 44.8, 47.9, 114.2, 139.4 . GC-MS (EI) $m / z$ (relative intensity) $=384\left(\left[\mathrm{M}^{+}\right], 6\right), 259(68), 149$ (100), 135 (41), 93 (27), 55 (26).

1,3-Di(dec-9-en-1-yl)adamantane (M-1,3-Ad-8). Yield: $74 \% .{ }^{1} \mathrm{H}$ $\operatorname{NMR}\left(850 \mathrm{MHz}, \mathrm{CDCl}_{3}\right): \delta(\mathrm{ppm})=1.01-1.06(\mathrm{~m}, 4 \mathrm{H}), 1.12-1.16$ (m, $2 \mathrm{H}), 1.17-1.24(\mathrm{~m}, 8 \mathrm{H}), 1.24-1.31(\mathrm{~m}, 12 \mathrm{H}), 1.31-1.42(\mathrm{~m}$, $12 \mathrm{H}), 1.55-1.57(\mathrm{~m}, 2 \mathrm{H}), 1.95-1.99(\mathrm{~m}, 2 \mathrm{H}), 2.02-2.07(\mathrm{~m}, 4 \mathrm{H})$, $4.90-4.95(\mathrm{~m}, 2 \mathrm{H}), 4.97-5.02(\mathrm{~m}, 2 \mathrm{H}), 5.82(\mathrm{ddt}, J=17.20,10.24$, $6.68 \mathrm{~Hz}, 2 \mathrm{H}) .{ }^{13} \mathrm{C}$ NMR $\left(214 \mathrm{MHz}, \mathrm{CDCl}_{3}\right): \delta(\mathrm{ppm})=22.7,29.1$, 29.3, 29.4, 29.7, 29.8, 30.8, 33.1, 34.0, 37.1, 42.4, 44.7, 47.7, 114.2, 139.4. GC-MS (EI) $m / z$ (relative intensity) $=412\left(\left[\mathrm{M}^{+}\right], 2\right), 273$ (43), 149 (100), 135 (54), 93 (31), 55 (27).

1,3-Di(undec-10-en-1-yl)adamantane (M-1,3-Ad-9). Yield: 53\%. ${ }^{1} \mathrm{H}$ NMR is representatively assigned for monomers $\mathbf{M - 1 , 3 - A d - m}$ in Figure S4. ${ }^{1} \mathrm{H}$ NMR $\left(850 \mathrm{MHz}, \mathrm{CDCl}_{3}\right): \delta(\mathrm{ppm})=1.01-1.07(\mathrm{~m}$, $4 \mathrm{H}), 1.14-1.16(\mathrm{~m}, 2 \mathrm{H}), 1.19-1.25(\mathrm{~m}, 8 \mathrm{H}), 1.25-1.33(\mathrm{~m}, 16 \mathrm{H})$, $1.33-1.44(\mathrm{~m}, 12 \mathrm{H}), 1.56-1.59(\mathrm{~m}, 2 \mathrm{H}), 1.96-2.00(\mathrm{~m}, 2 \mathrm{H}), 2.02-$ $2.07(\mathrm{~m}, 4 \mathrm{H}), 4.90-4.96(\mathrm{~m}, 2 \mathrm{H}), 4.97-5.03(\mathrm{~m}, 2 \mathrm{H}), 5.82(\mathrm{ddt}, J=$ $17.25,10.26,6.66 \mathrm{~Hz}, 2 \mathrm{H}) .{ }^{13} \mathrm{C} \mathrm{NMR}\left(214 \mathrm{MHz} \mathrm{CDCl}_{3}\right): \delta(\mathrm{ppm})=$ $22.7,29.2,29.3,29.5,29.7,29.8,29.9,30.9,33.2,34.0,37.2,42.5$, $44.8,47.9,114.2$, 139.4. GC-MS (EI) $\mathrm{m} / z$ (relative intensity) $=440$ ([ $\left.\left.\mathrm{M}^{+}\right], 2\right), 287$ (57), 149 (100), 135 (60), 93 (29), 55 (27).

General Experimental Procedure for Polymer Synthesis and Hydrogenation ( $P-1,3-A d-Z, Z=10,16,18$, and 20; and CP1,3-Ad-16/18/20). A flame-dried Schlenk tube equipped with a stir bar was charged with 1,3-adamantyl dienes (M-1,3-Ad-m, $m=4,7,8$, and 9) (1.00 equiv) for homopolymerization or an equimolar mixture of M-1,3-Ad-7 (0.50 equiv) and M-1,3-Ad-9 (0.50 equiv) for copolymerization. The monomer was degassed in the liquid state over $2 \mathrm{~h}$ by alternating evacuation in vacuo $\left(10^{-3} \mathrm{mbar}\right)$ and purging with argon. Grubbs catalyst 1st generation ( 0.03 equiv) was added under argon to the monomer. Polymerization was carried out at reduced pressure at ambient temperature for $2 \mathrm{~h}$ and for $24 \mathrm{~h}$ at $65^{\circ} \mathrm{C}$. The polymers were obtained as brown viscous materials, diluted in toluene $(2 \mathrm{~mL})$, and participated in cold methanol $(30 \mathrm{~mL})$. This procedure was repeated twice. Viscous polymers were dried, followed by hydrogenation. Unsaturated polymers (1.00 equiv) were dissolved in $o$-xylene $(10-12 \mathrm{~mL})$. Tripropylamine (3.80 equiv) and toluenesulfonohydrazide (3.00 equiv) were added. The solution was than heated to $135{ }^{\circ} \mathrm{C}$ with vigorous stirring for $24 \mathrm{~h}$, followed by another addition of tripropylamin (3.80 equiv) and toluenesulfonohydrazide (3.00 equiv). Subsequently, the mixtures were cooled to rt and poured into cold methanol to form a colorless participate. The colorless polymers were dried in vacuo.

P-1,3-Ad-10. ${ }^{1} \mathrm{H}$ NMR $\left(850 \mathrm{MHz}, \mathrm{CDCl}_{3}\right): \delta(\mathrm{ppm})=0.99-1.06$ (m, 4H), 1.12-1.15 (m, 2H), 1.17-1.23 (m, 8H), 1.24-1.30 (m, $8 \mathrm{H}), 1.31-1.44(\mathrm{~m}, 8 \mathrm{H}), 1.53-1.59(\mathrm{~m}, 2 \mathrm{H}), 1.95-2.00(\mathrm{~m}, 2 \mathrm{H})$. ${ }^{13} \mathrm{C}$ NMR $\left(214 \mathrm{MHz} \mathrm{CDCl}_{3}\right): \delta(\mathrm{ppm})=22.7,29.4,29.9,29.9,30.9$, 33.1, 37.1, 42.4, 44.8, 47.8.

P-1,3-Ad-16. ${ }^{1} \mathrm{H}$ NMR $\left(850 \mathrm{MHz}, \mathrm{CDCl}_{3}\right): \delta(\mathrm{ppm})=1.00-1.06$ (m, 4H), 1.12-1.16 (m, 2H), 1.17-1.29 (m, 28H), 1.31-1.45 (m, $8 \mathrm{H}), 1.53-1.59\left(\mathrm{~m}, 2 \mathrm{H},+\mathrm{H}_{2} \mathrm{O}\right), 1.93-2.01(\mathrm{~m}, 2 \mathrm{H}) .{ }^{13} \mathrm{C}$ NMR $(214$ $\left.\mathrm{MHz} \mathrm{CDCl}_{3}\right): \delta(\mathrm{ppm})=22.7,29.4,29.9,29.9,29.9,30.9,33.1,37.1$, 42.4, 44.8, 47.8.
P-1,3-Ad-18. ${ }^{1} \mathrm{H}$ NMR (850 MHz, $\left.\mathrm{CDCl}_{3}\right): \delta$ (ppm) = 1.00-1.06 $(\mathrm{m}, 4 \mathrm{H}), 1.12-1.15(\mathrm{~m}, 2 \mathrm{H}), 1.16-1.31(\mathrm{~m}, 32 \mathrm{H}), 1.31-1.42(\mathrm{~m}$, $8 \mathrm{H}), 1.53-1.58\left(\mathrm{~m}, 2 \mathrm{H},+\mathrm{H}_{2} \mathrm{O}\right), 1.95-1.99(\mathrm{~m}, 2 \mathrm{H})$.

${ }^{13} \mathrm{C}$ NMR $\left(214 \mathrm{MHz} \mathrm{CDCl}_{3}\right): \delta(\mathrm{ppm})=22.7,29.4,29.9,29.9$, 30.9, 33.1, 42.4, 44.8, 47.8.

P-1,3-Ad-20. ${ }^{1} \mathrm{H}$ NMR $\left(850 \mathrm{MHz}, \mathrm{CDCl}_{3}\right): \delta(\mathrm{ppm})=1.01-1.05$ (m, $4 \mathrm{H}), 1.12-1.15(\mathrm{~m}, 2 \mathrm{H}), 1.15-1.32(\mathrm{~m}, 36 \mathrm{H}), 1.32-1.43(\mathrm{~m}$, $8 \mathrm{H}), 1.55-1.57(\mathrm{~m}, 2 \mathrm{H}), 1.93-2.01(\mathrm{~m}, 2 \mathrm{H}) .{ }^{13} \mathrm{C}$ NMR $(214 \mathrm{MHz}$ $\left.\mathrm{CDCl}_{3}\right): \delta(\mathrm{ppm})=22.7,29.4,29.9,29.9,30.9,33.1,42.4,44.8,47.8$.

CP-1,3-Ad-16/18/20. ${ }^{1} \mathrm{H}$ NMR (700 MHz, $\left.\mathrm{CDCl}_{3}\right): \delta(\mathrm{ppm})=$ $0.98-1.09(\mathrm{~m}, 4 \mathrm{H}), 1.10-1.18(\mathrm{~m}, 2 \mathrm{H}), 1.18-1.30(\mathrm{~m}, 32 \mathrm{H}), 1.31-$ $1.43(\mathrm{~m}, 8 \mathrm{H}), 1.51-1.55\left(\mathrm{~m}, 2 \mathrm{H},+\mathrm{H}_{2} \mathrm{O}\right), 1.94-2.00(\mathrm{~m}, 2 \mathrm{H})$.

${ }^{13} \mathrm{C}$ NMR $\left(176 \mathrm{MHz} \mathrm{CDCl}_{3}\right): \delta(\mathrm{ppm})=22.7,29.4,29.9,29.9$, $30.9,33.1,42.4,44.8,47.8$.

\section{ASSOCIATED CONTENT}

\section{Supporting Information}

The Supporting Information is available free of charge on the ACS Publications website at DOI: 10.1021/acs.macromol.9b00294.

\section{Analytical and spectral characterization data (PDF)}

\section{AUTHOR INFORMATION}

\section{Corresponding Authors}

*E-mail: wagener@chem.ufla.edu (K.B.W.).

*E-mail: weil@mpip-mainz.mpg.de (T.W.).

ORCID

Markus Mezger: 0000-0001-9049-6983

Jasper Michels: 0000-0003-1591-4449

Kenneth B. Wagener: 0000-0001-9542-0259

Tanja Weil: 0000-0002-5906-7205

\section{Author Contributions}

The manuscript was written through contributions of all authors. All authors have given approval to the final version of the manuscript.

\section{Funding}

This work has received funding from the Max Planck Society and the European Union.

\section{Notes}

The authors declare no competing financial interest.

\section{ACKNOWLEDGMENTS}

The authors are grateful to the support from the Max Planck Society. T.W. acknowledges financial support by the European Research Council for a Synergy Grant (319130-BioQ) and by the European Union for the Horizon 2020 project "Hyperdiamond" under the grant agreement No. 667192.

\section{REFERENCES}

(1) Fort, R. C.; Schleyer, P. V. R. Adamantane: Consequences of the Diamondoid Structure. Chem. Rev. 1964, 64, 277-300.

(2) Balaban, A. T.; Schleyer, P. V. R. Systematic Classification and Nomenclature of Diamond Hydrocarbons-I: Graph-Theoretical Enumeration of Polymantanes. Tetrahedron 1978, 34, 3599-3609.

(3) Schwertfeger, H.; Fokin, A. A.; Schreiner, P. R. Diamonds Are a Chemist's Best Friend: Diamondoid Chemistry Beyond Adamantane. Angew. Chem., Int. Ed. 2008, 47, 1022-1036.

(4) Gunawan, M. A.; Hierso, J. C.; Poinsot, D.; Fokin, A. A.; Fokina, N. A.; Tkachenko, B. A.; Schreiner, P. R. Diamondoids: Functionalization and Subsequent Applications of Perfectly Defined Molecular Cage Hydrocarbons. New J. Chem. 2014, 38, 28-41.

(5) Somlai, L. S.; Lewis, C. M.; Mathias, L. J.; Schiraldi, D. A. Synthesis and Characterization of Novel Ethylene Glycol Polyesters 
Containing Terephthalic and 5-Adamantylisophthalic Acids. Des. Monomers Polym. 2003, 6, 123-133.

(6) Mansoori, G. A. Diamondoid Molecules. Adv. Chem. Phys. 2007, 136, 207-258.

(7) Mansoori, G. A.; Araújo, P.; Araujo, E. Diamondoid Molecules: With Applications in Biomedicine, Materials Science, Nanotechnology \& Petroleum Science. World Sci. 2012, 1-408.

(8) Castillo, J. A.; Borchmann, D. E.; Cheng, A. Y.; Wang, Y.; Hu, C.; García, A. J.; Weck, M. Well-Defined Poly(Lactic Acid)s Containing Poly(Ethylene Glycol) Side Chains. Macromolecules 2012, 45, 62-69.

(9) Wu, K.-H.; Wang, J.-C.; Chang, Y.-C.; Li, F.-N.; Tsai, C.-W. Synthesis of Adamantane-Containing Methacrylate Polymers: Characterization of Thermal, Mechanical, Dielectric and Optical Properties. Mater. Express 2016, 6, 220-228.

(10) Ishizone, T.; Goseki, R. Synthesis of Polymers Carrying Adamantyl Substituents in Side Chain. Polym. J. 2018, 50, 805-819.

(11) Van Reenen, A. J.; Mathias, L. J.; Coetzee, L. Polymerization of Olefins with Bulky Substituents. 1. Homo- and Copolymerization of 3-(1-Adamantyl)Propene. Polymer 2004, 45, 799-804.

(12) Spohn, M.; Alkahtani, M. H. A.; Leiter, R.; Qi, H.; Kaiser, U.; Hemmer, P.; Ziener, U. Poly(1-Vinyladamantane) as a Template for Nanodiamond Synthesis. ACS Appl. Nano Mater. 2018, 1, 60736080.

(13) Okano, Y.; Masuda, T.; Higashimura, T. Polymerization of Tert-Alkylacetylenes by Mo- and W-Based Catalysts. J. Polym. Sci., Polym. Chem. Ed. 1985, 23, 2527-2537.

(14) Kobayashi, S.; Kataoka, H.; Ishizone, T. Synthesis of WellDefined Poly(Ethylene- Alt -1-Vinyladamantane) via Living Anionic Polymerization of 2-(1-Adamantyl)-1,3-Butadiene, Followed by Hydrogenation. Macromolecules 2009, 42, 5017-5026.

(15) Kobayashi, S.; Kataoka, H.; Ishizone, T.; Kato, T.; Ono, T.; Kobukata, S.; Arimoto, K.; Ogi, H. Synthesis of Well-Defined Random and Block Copolymers of 2-(1-Adamantyl)-1,3-Butadiene with Isoprene via Anionic Polymerization. React. Funct. Polym. 2009, 69, 409-415.

(16) Rojas, G.; Inci, B.; Wei, Y.; Wagener, K. B. Precision Polyethylene: Changes in Morphology as a Function of Alkyl Branch Size. J. Am. Chem. Soc. 2009, 131, 17376-17386.

(17) Reinhardt, H. F. Polyadamantane. J. Polym. Sci., Part B: Polym. Lett. 1964, 2, 567-568.

(18) Pincock, R. E.; Torupka, E. J. Tetracyclo[3.3.1.13,7.01,3]Decane. Highly Reactive 1,3-Dehydro Derivative of Adamantane. J. Am. Chem. Soc. 1969, 91, 4593.

(19) Ishizone, T.; Matsuoka, S. I.; Sakai, S.; Harada, W.; Tajima, H. Synthesis of Poly(1,3-Adamantane)s by Cationic Ring-Opening Polymerization of 1,3-Dehydroadamantanes. Macromolecules 2004, 37, 7069-7071.

(20) Inomata, S.; Matsuoka, S. I.; Sakai, S.; Tajima, H.; Ishizone, T. Ring-Opening Polymerizations of 1,3-Dehydroadamantanes: Synthesis of Novel Thermally Stable Poly(1,3-Adamantane)S. Macromolecules 2012, 45, 4184-4195.

(21) Schulz, M. D.; Wagener, K. B. Precision Polymers through ADMET Polymerization. Macromol. Chem. Phys. 2014, 215, 19361945.

(22) Baltá-Calleja, F. J.; Hosemann, R. Distribution of Chain Defects and Microstructures of Melt Crystallized Polyethylene. II. Influence of Defect Size and of Plastic Deformation. J. Polym. Sci., Polym. Phys. Ed. 1980, 18, 1159-1165.

(23) Zheng, Y. R.; Tee, H. T.; Wei, Y.; Wu, X. L.; Mezger, M.; Yan, S.; Landfester, K.; Wagener, K.; Wurm, F. R.; Lieberwirth, I. Morphology and Thermal Properties of Precision Polymers: The Crystallization of Butyl Branched Polyethylene and Polyphosphoesters. Macromolecules 2016, 49, 1321-1330.

(24) Sauty, N. F.; Caire Da Silva, L.; Gallagher, C.; Graf, R.; Wagener, K. B. Unveiling the Hyperbolic Thermal Behaviour of Poly(p-Phenylene Alkylene)S. Polym. Chem. 2015, 6, 6073-6082.

(25) Da Silva, L. C.; Wagener, K. B. Synthesis and Thermal Characterization of Precision Poly(p-Cyclohexylene Alkylene)s via
Acyclic Diene Metathesis Polycondensation. Macromol. Chem. Phys. 2016, 217, 850-855.

(26) Song, S.; Miao, W.; Wang, Z.; Gong, D.; Chen, Z.-R. Synthesis and Characterization of Precisely-Defined Ethylene-Co-Aryl Ether Polymers via ADMET Polymerization. Polymer 2015, 64, 76-83.

(27) Song, S.; Guo, W.; Zou, S.; Fu, Z.; Xu, J.; Fan, Z. Polyethylene Containing Aliphatic Ring and Aromatic Ring Defects in the Main Chain: Synthesis via ADMET and Comparisons of Thermal Properties and Crystalline Structure. Polymer 2016, 107, 113-121.

(28) Song, S. F.; Guo, Y. T.; Wang, R. Y.; Fu, Z. S.; Xu, J. T.; Fan, Z. Q. Synthesis and Crystallization Behavior of Equisequential ADMET Polyethylene Containing Arylene Ether Defects: Remarkable Effects of Substitution Position and Arylene Size. Macromolecules 2016, 49, 6001-6011.

(29) Rojas, G.; Baughman, T. W.; Wagener, K. B. Quantitative $\alpha$ Alkylation of Primary Nitriles. Synth. Commun. 2007, 37, 3923-3931.

(30) Rojas, G.; Wagener, K. B. Avoiding Olefin Isomerization During Decyanation of Alkylcyano $\alpha, \omega$-Dienes: A Deuterium Labeling and Structural Study of Mechanism. J. Org. Chem. 2008, 73, 4962-4970.

(31) Terao, J.; Todo, H.; Begum, S. A.; Kuniyasu, H.; Kambe, N. Copper-Catalyzed Cross-Coupling Reaction of Grignard Reagents with Primary-Alkyl Halides: Remarkable Effect of 1-Phenylpropyne. Angew. Chem., Int. Ed. 2007, 46, 2086-2089.

(32) Iwasaki, T.; Imanishi, R.; Shimizu, R.; Kuniyasu, H.; Terao, J.; Kambe, N. Copper-Catalyzed Alkyl-Alkyl Cross-Coupling Reactions Using Hydrocarbon Additives: Efficiency of Catalyst and Roles of Additives. J. Org. Chem. 2014, 79, 8522-8532.

(33) Hahn, S. F. An Improved Method for the Diimide Hydrogenation of Butadiene and Isoprene Containing Polymers. J. Polym. Sci., Part A: Polym. Chem. 1992, 30, 397-408.

(34) Frank, F. C. General Introduction. Faraday Discuss. Chem. Soc. 1979, 68, 7-13.

(35) Richardson, M. J. Thermodynamic Behaviour of Polyethylene Single Crystals. Trans. Faraday Soc. 1965, 61, 1876-1886.

(36) Weiss, H.; Mars, J.; Li, H.; Kircher, G.; Ivanova, O.; Feoktystov, A.; Soltwedel, O.; Bier, M.; Mezger, M. Mesoscopic Correlation Functions in Heterogeneous Ionic Liquids. J. Phys. Chem. B 2017, 121, 620-629.

(37) Fokin, A. A.; Butova, E. D.; Barabash, A. V.; Huu, N. N.; Tkachenko, B. A.; Fokina, N. A.; Schreiner, P. R. Preparative Synthesis of Vinyl Diamondoids. Synth. Commun. 2013, 43, 17721777.

(38) Reichle, M. A.; Breit, B. Preparation of Alkylmagnesium Reagents from Alkenes through Hydroboration and Boron-Magnesium Exchange. Angew. Chem., Int. Ed. 2012, 51, 5730-5734. 